\title{
HealthAffairs
}

At the Intersection of Health, Health Care and Policy

Cite this article as:

Bobby Milstein, Jack Homer, Peter Briss, Deron Burton and Terry Pechacek Why Behavioral And Environmental Interventions Are Needed To Improve Health At Lower Cost

Health Affairs, 30, no.5 (2011):823-832

doi: $10.1377 /$ hlthaff.2010.1116

The online version of this article, along with updated information and services, is available at:

http://content.healthaffairs.org/content/30/5/823.full.html

For Reprints, Links \& Permissions:

http://healthaffairs.org/1340_reprints.php

E-mail Alerts : http://content.healthaffairs.org/subscriptions/etoc.dtl

To Subscribe: http://content.healthaffairs.org/subscriptions/online.shtml

Health Affairs is published monthly by Project HOPE at 7500 Old Georgetown Road, Suite 600, Bethesda, MD 20814-6133. Copyright (C 2011 by Project HOPE - The People-to-People Health Foundation. As provided by United States copyright law (Title 17, U.S. Code), no part of Health Affairs may be reproduced, displayed, or transmitted in any form or by any means, electronic or mechanical, including photocopying or by information storage or retrieval systems, without prior written permission from the Publisher. All rights reserved. 


\section{Why Behavioral And Environmental Interventions Are Needed To Improve Health At Lower Cost}

ABSTRACT We used a dynamic simulation model of the US health system to test three proposed strategies to reduce deaths and improve the costeffectiveness of interventions: expanding health insurance coverage, delivering better preventive and chronic care, and protecting health by enabling healthier behavior and improving environmental conditions. We found that each alone could save lives and provide good economic value, but they are likely to be more effective in combination. Although coverage and care save lives quickly, they tend to increase costs. The impact of protection grows more gradually, but it is a critical ingredient over time for lowering both the number of deaths and reducing costs. Only protection slows the growth in the prevalence of disease and injury and thereby alleviates rather than exacerbates demand on limited primary care capacity. When added to a simulated scenario with coverage and care, protection could save 90 percent more lives and reduce costs by 30 percent in year 10; by year 25, that same investment in protection could save about 140 percent more lives and reduce costs by 62 percent.

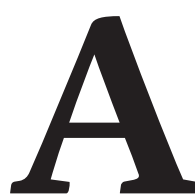
mericans are engaged in a longstanding quest to fundamentally improve the US health system. The Affordable Care Act of 2010 instituted a range of provisions to expand insurance coverage; improve health care delivery; and also protect the population's wellbeing by enabling healthier conditions in homes, workplaces, schools, neighborhoods, and other locations.

As this law is implemented and other steps are taken to create a more healthful and affordable system, it is useful to question how these three basic intervention strategies-coverage, care, and protection-affect the nation's health and economic outcomes, individually or together. How much of an impact can each component have? Are their effects complementary or synergistic? How fast can they yield results-and how long might those effects last? Answering these questions requires a macroscopic analysis of the health system as a whole, with attention to the dynamic processes that connect its distinct parts and produce changes over time.

We estimated the relative and combined health and economic impacts from expanding health insurance (referred to in the rest of this paper as coverage); delivering better preventive and chronic care (referred to as care), and enabling healthier behavior and safer environments (referred to as protection). Our study did not analyze the probable effects of the implementation of the Affordable Care Act. Instead, we began all simulation experiments in the early 2000s (based on data availability) and asked what might have happened had the United States taken decisive action in these three areas about a decade ago.

In particular, we considered each strategy separately and together by charting their likely consequences over a twenty-five-year period. A review of these alternative trajectories may help
DOI: $10.1377 /$ hlthaff.2010.1116 HEALTH AFFAIRS 30 , NO. 5 (2011): 823-832 (c)2011 Project HOPEThe People-to-People Health Foundation, Inc
Bobby Milstein (bmilstein@ cdc.gov) is the coordinator for the Syndemics Prevention Network at the Centers for Disease Control and

Prevention, in Atlanta, Georgia.

Jack Homer is president of Homer Consulting, in Voorhees, New Jersey.

Peter Briss is the medical director of the National Center for Chronic Disease Prevention and Health Promotion, at the Centers for Disease Control and Prevention.

\section{Deron Burton is a}

Commissioned Corps officer at the Center for Global Health, at the Centers for Disease Control and Prevention.

Terry Pechacek is the associate director for science of the Office on Smoking and Health, at the Centers for Disease Control and Prevention. 
planners better evaluate their options moving forward.

\section{Study Data And Methods}

This analysis builds on a previously published mathematical model of the US health system developed by the Centers for Disease Control and Prevention (CDC). With input from diverse stakeholders, subject-matter experts, and system scientists, analysts in the agency created the HealthBound policy simulation model to bring more structure, evidence, and creativity to bear on strategic questions about national health policy. ${ }^{2}$

No analysis can precisely represent the current state of the US health system, if only because the necessary data involve reporting delays and inevitable uncertainties. We were, however, able to closely approximate observed conditions in the United States around 2003, the last year for which key data were available. The model also relied on numerical assumptions tied to ten national databases, ${ }^{3}$ as well as key reference studies (listed in the Appendix). ${ }^{4}$

Being imperfect, as all models are, this tool does not produce exact forecasts, nor can it predict the effects of a specific initiative or legislative action. It does, however, offer a useful way of seeing how the US health system tends to respond to large-scale interventions. Simulated scenarios let planners compare major types of interventions based on their respective direction and timing, as well as the magnitude of expected costs and benefits.

MODEL OVERVIEW The model's structure and data sources have been described elsewhere. ${ }^{1}$ In brief, HealthBound is a deterministic, differential equations-type model built according to the methodology of system dynamics modeling. ${ }^{5,6} \mathrm{It}$ features several hundred interacting elements that describe essential relationships at the national level that affect population health status, health equity, and health care costs over time. Many sorts of national policies-spanning health care delivery and financing as well as behavioral, environmental, and social interventions-can be compared within this single analytic framework.

For this analysis we extended a previously published version of the model to create a more realistic status quo scenario that incorporated conservative estimates for health care price inflation and population aging (see the Appendix). ${ }^{4}$ Over a twenty-five-year period, this revised status quo scenario showed steady and sizable increases in mortality and health care costs. We compared all of the intervention scenarios described here to this status quo scenario. In each simulation, the interventions go into effect at Time 0 (circa 2003) and remain in effect throughout twenty-five years.

INTERVENTION ANALYSIS We compared each simulated intervention to the status quo scenario along two summary measures: deaths prevented and costs. Deaths can be prevented in the model by providing better care for people with existing diseases and injuries, or by preventing disease and injury in the first place. The coverage and care interventions do some of each directly, by increasing the number of patients receiving appropriate disease and injury management (chronic care) as well as through clinical riskfactor management (preventive care).

The direct effects of protection, in contrast, are purely preventive, because this strategy improves both health-related behavior and environmental conditions that affect the onset of disease and injury. By reducing demand on the health care delivery system, protection also helps alleviate the shortage of clinical capacity to care for people with existing health problems. In this indirect way it can also ultimately lead to more people's getting better care. All of these effects, both direct and indirect, are calculated in the model.

The cost metric combines health care costs and the estimated costs of implementing the interventions. The model includes all reported health care costs associated with personal health services provided by hospitals, office-based physicians, nursing homes and home health care, and dental and other health care providers; prescription drugs; other medical products; and administrative costs of health insurance. Together, these account for more than 90 percent of all health-related spending in the United States. ${ }^{7}$

Intervention costs are more difficult to estimate, especially for broad classes of interventions that may be implemented through diverse strategies. For this analysis we tested both higher and lower estimates to reflect the uncertainty about practical intervention details. The range of uncertainty varies according to the available evidence: The widest interval is associated with protection, followed by care and then coverage. When reporting cost results on a cumulative basis, we applied an annual discount rate of 3 percent. ${ }^{8,9}$

Parameters for the direct health effects and implementation costs for each intervention were set using baseline estimates as well as uncertainty ranges that run from "pessimistic" (that is, a less effective and more costly scenario) to "optimistic" (that is, a more effective and less costly scenario). For each simulated scenario, we accordingly report baseline, pessimistic, and optimistic results (see the Appendix for 
parameter values). ${ }^{4}$

We report cumulative results for deaths and time-discounted costs at years 10 and 25. A ten-year time horizon is generally used by the Congressional Budget Office, but this time frame has been criticized as inadequate to show the full effects of interventions that prevent disease onset or alter the trajectories of chronic diseases. ${ }^{10}$ Thus, we show longer-term results as well.

Previous analyses using this model have shown that expanding primary care capacity can greatly enhance the ability of coverage and care interventions to improve health and costeffectiveness. ${ }^{1}$ We therefore conducted sensitivity tests to examine how the sufficiency of primary care capacity might affect each simulated scenario. Those tests, reported in the Appendix, ${ }^{4}$ did not meaningfully alter the overall pattern of results.

\section{INTERVENTION SCENARIOS}

D EXTENDING HEALTH INSURANCE (COVERAGE): A simulated intervention to extend health insurance to all people, similar to ongoing programs in Massachusetts ${ }^{11}$ and probably covering a larger proportion of the population than will be achieved under the Affordable Care Act, causes the uninsured fraction of the US population to decline from its status quo starting value of 15.6 percent to 5 percent by year 3 , and to less than 1 percent by year 8 and beyond. The cost impacts of this intervention include the greater costs of the additional services and medical products used by the newly insured, minus cost savings from fewer hospitalizations and visits to the emergency department. The costs also include outlays for providing health care to those whose deaths are averted as a result of the reduction of these events, as well as the costs of administering the insurance program.

Based on the Massachusetts experience, we assumed that the amortized cost of administering the program was $\$ 20$ per additional person covered per year (uncertainty range: \$10-\$40).

- DELIVERING BETTER PREVENTIVE AND CHRONIC CARE (CARE): Research suggests that it is possible to deliver better health care-particularly preventive and chronic care-in the United States, where adherence to recommended guidelines for disease and injury screening and management is relatively low. ${ }^{12-15} \mathrm{~A}$ simulated intervention to improve providers' adherence to guidelines for preventive and chronic care causes such adherence to rise relatively quickly from its status quo value of 70 percent, ${ }^{16}$ reaching about 83 percent (uncertainty range: $80-86$ percent) by year 5 and stabilizing at 85 percent (uncertainty range: $82-88$ percent) by year 9 .

The Appendix describes how this intervention operates within the model and presents evidence of its potential impact. ${ }^{4}$ We assumed that the amortized cost of programs to help office-based providers adhere to quality guidelines was $\$ 10,000$ (uncertainty range: $\$ 2,000-\$ 20,000$ ) per physician per year.

A number of real-world interventions have been shown to close gaps in appropriate health care delivery. ${ }^{13}$ These involve, for example, health information systems oriented toward prevention, which trigger interventions such as reminder systems to boost the delivery of effective care; practice work flows that support prevention; and efforts to help patients take a greater role in their own care. All of these may be increasingly feasible with the continuing development of electronic health records.

Similar efforts to deliver better preventive and chronic care could begin by identifying a set of high-value services that merit greater attention. For example, cardiovascular disease is the leading cause of death in the United States, and a number of clearly cost-effective preventive services are available that could greatly reduce its burden. These include the greater use of aspirin by people at risk of recurrent heart attacks or strokes, improved diagnosis and treatment of high blood pressure and high cholesterol, and greater use of smoking cessation treatment. ${ }^{17}$ The current delivery of some of these services remains low, ${ }^{18}$ however, and improvements in health care systems to improve their use could yield important health benefits.

- ENABLING HEALTHIER BEHAVIOR AND SAFER ENVIRONMENTS (PROTECTION): Researchers have shown that many interventions to enable healthier behavior and improve environmental safety can produce effects immediately and are likely to yield cost-effective, if not cost-saving, returns-but it generally takes several years before they have their full impact. ${ }^{19-23}$ Given the variety of opportunities available in this policy domain, we modeled behavioral and environmental interventions using aggregate estimates of effectiveness and uncertainty, representing the potential impact across this diverse class of strategies to reduce risk and vulnerability in the population at large.

In the simulation, the behavioral intervention caused the fraction of the population engaging in risky behavior such as smoking or physical inactivity to decline from its status quo starting value of 34 percent $^{24}$ to about 23 percent (uncertainty range: $22-25$ percent) by year 5 , stabilizing at 19.5 percent (uncertainty range: $18-21$ percent) by year 16 . Similarly, the environmental intervention caused the fraction of the population exposed to unsafe environments-because of air pollution or injury hazards-to decline 
from its status quo starting value of 27 percent ${ }^{25}$ to about 18 percent (uncertainty range: 1719 percent) by year 5 , stabilizing at 15 percent (uncertainty range: 14-15.5 percent) by year 16 .

As above, the Appendix describes how these interventions operate within the model and presents evidence of their potential impact. ${ }^{4}$ We assumed that the costs were $\$ 2,000$ per beneficiary for the behavioral intervention (uncertainty range: $\$ 200-\$ 5,000)$, and $\$ 500$ per beneficiary for the environmental intervention (uncertainty range: $\$ 200-\$ 3,000$ ), cumulated over twenty-five years as more individuals benefited. ${ }^{26}$

We also assumed that the interventions were designed to focus on portions of the population most likely to benefit, although in fact not all of the members of these groups will successfully change their behavior. The costs per beneficiary therefore reflect total expenditures, for those who benefit and those who do not.

A number of real-world interventions have improved behavioral and environmental conditions (see the Appendix). ${ }^{4}$ For instance, specific studies have recorded considerable progress in reducing tobacco use, ${ }^{27,28}$ secondhand smoke exposure ${ }^{29}$ consumption of saturated and trans fats, ${ }^{30-32}$ physical inactivity, ${ }^{33}$ exposure to air pollution, ${ }^{34}$ and alcohol-impaired driving,,$^{35}$ among others. These are some of the many types of interventions consistent with the protection scenario that we tested.

Improvements in behavioral and environmental conditions have, in turn, clearly improved population health. Some exemplary achievements have reduced deaths, diseases, and disabilities resulting from, for example, lead poisoning, motor vehicle injuries, dental caries, foodborne illness, workplace injuries, and infectious diseases. ${ }^{21}$ One of the most dramatic accomplishments on record is the large decline in cardiovascular disease mortality in the latter half of the twentieth century, which was achieved through coordinated interventions to reduce multiple behavioral and environmental risks and also improve clinical care. ${ }^{36}$

To further strengthen population-based prevention in the years ahead, planners could focus on the risks and hazards that have the greatest impact across the country. A recent analysis identified twelve risks in the United States that were each estimated to account for approximately 15,000-500,000 potentially preventable deaths annually. ${ }^{37}$ Some of the modifiable risks in the study that imposed the highest burden were smoking, overweight and obesity, physical inactivity, high dietary sodium, alcohol use, and low consumption of fruits and vegetables. Other environmental factors, such as fine-particulate air pollution, ${ }^{38}$ and policies, such as regulations to prevent motor vehicle-related injuries, ${ }^{39}$ are also important.

Many of these threats to population health can be reduced through the wider implementation of available interventions, including those recommended by the US Task Force on Community Preventive Services. ${ }^{19}$ Another source of intervention guidance is the CDC's Vital Signs series, which features monthly publications on topics such as tobacco control, ${ }^{40}$ physical activity and healthy eating, ${ }^{41}$ high blood pressure and cholesterol, ${ }^{42}$ seat belt use, ${ }^{39}$ and binge drinking. ${ }^{43}$

Of course, full and sustained implementation of these initiatives is needed. For example, with respect to smoking-still the largest cause of preventable death-if all US states were to fund comprehensive tobacco control programs annually at the levels that the $\mathrm{CDC}$ recommends, after five years an estimated five million fewer people would smoke, and hundreds of thousands of tobacco-related deaths would be prevented. ${ }^{44}$

Recognizing that much more could be done in all three of these broad policy domains-coverage, care, and protection-the analysis below helps characterize the relative benefits and costs for each of them, alone and in combination, over a period of twenty-five years.

\section{Study Results}

INDIVIDUAL INTERVENTION SCENARIOS EXhibit 1 displays the results from simulating each intervention individually through years 10 and 25 . After ten years, the status quo scenario results in twenty-two million deaths and cumulative discounted health care costs of $\$ 14$ trillion. Compared to that scenario, the simulated coverage intervention would prevent 269,000 deaths; the care intervention, 953,000; and the protection intervention, 721,000. With regard to costs, the coverage intervention would increase cumulative discounted costs by $\$ 527$ billion, the care intervention by $\$ 416$ billion, and the protection intervention by $\$ 179$ billion.

Thus, in the first ten years all three interventions were likely to prevent many avoidable deaths, with the most lives saved by the care intervention, followed by protection and then coverage. The ten-year cumulative costs were lowest for protection, followed by care and then coverage, in both the baseline and the optimistic estimates. In the pessimistic estimate, these costs were highest for protection because the assumed up-front investment was so large that ten years was not long enough to accumulate sufficient health care savings to offset it.

After twenty-five years, the profile of simulated results changed substantially (Exhibit 1). By 
Deaths Prevented And Change In Health Care Costs Plus Program Spending, Three Intervention Scenarios, At Year 10 And Year 25

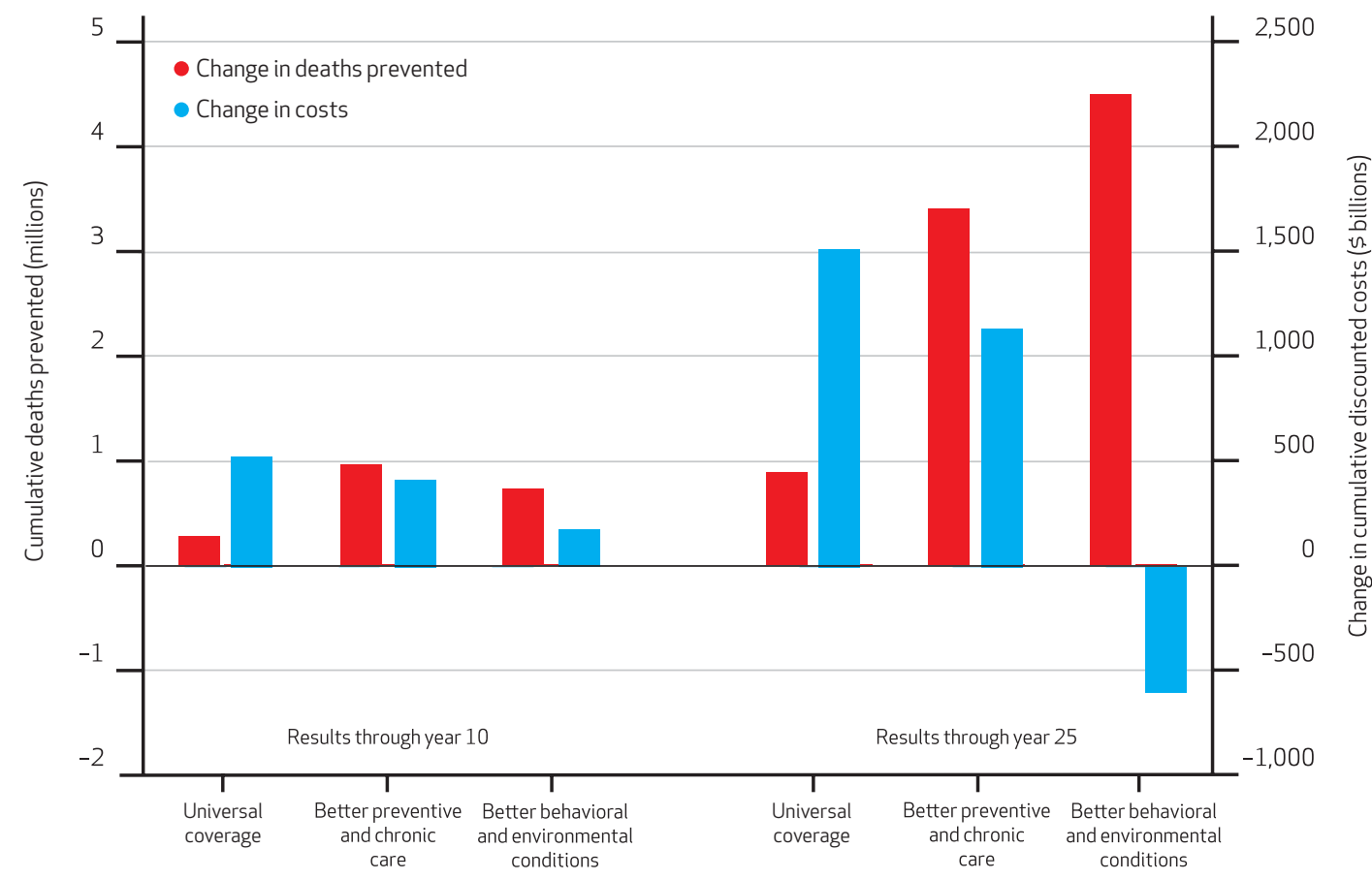

SOURCE Authors' analysis of the HealthBound policy simulation model. notes Red bars indicate cumulative deaths prevented-that is, the cumulative number of deaths in the status quo scenario minus those in an intervention scenario-and relate to the left-hand $y$ axis. Blue bars indicate the change (relative to the status quo scenario) in cumulative discounted costs, which include both health care costs and intervention program costs; this relates to the right-hand $y$ axis. Both sets of bars reflect results under the baseline uncertainty estimate. A version of the exhibit indicating pessimistic and optimistic estimates is available in the Appendix (see Note 4 in text).

then the status quo scenario would result in sixty-four million deaths and cumulative discounted health care costs of $\$ 31.5$ trillion. Compared to that scenario, the coverage intervention would prevent 880,000 deaths; the care intervention, 3.4 million; and the protection intervention, 4.5 million. The coverage intervention would increase cumulative discounted costs by $\$ 1.513$ trillion, and the care intervention would increase them by $\$ 1.134$ trillion. In contrast, the protection intervention would save $\$ 596$ billion.

Thus, with respect to these metrics after twenty-five years, a focus on protection-that is, improving behavioral and environmental conditions-is likely to be both the most effective and the least costly intervention, followed by better preventive and chronic care, and then wider insurance coverage.

LAYERED INTERVENTION SCENARIO RESULTS These three intervention domains are not mutually exclusive. In fact, they complement one another to yield a stronger combined strategy for health system improvement. Wider insurance coverage and better preventive and chronic care could work together to boost the effectiveness of health care services. But coverage and care also increase the demand for health care. In contrast, efforts to enable healthier behavior and build safer environments could reduce the prevalence of avoidable diseases and injuries, thereby protecting health longer and easing the demand for health care. Protection may thus offer a way to avoid the health care shortages that could result if coverage or care were implemented alone.

As the previous section shows, the coverage, care, and protection interventions differ in their short- and long-term effects. In analyses of combined scenarios, it is useful to follow each outcome metric over time to see how far and how fast the trajectories of deaths and costs change under different approaches. Exhibits 2 and 3 show simulated curves for deaths and costs, respectively, relative to the status quo scenario. Both exhibits show coverage alone, coverage combined with care, and all three interventions together. ${ }^{45}$ The added contribution of each new component can be measured by comparing it to the previous scenario. 


\section{EXHIBIT 2}

Annual Deaths, Three Layered Intervention Scenarios, Year 0 To Year 25

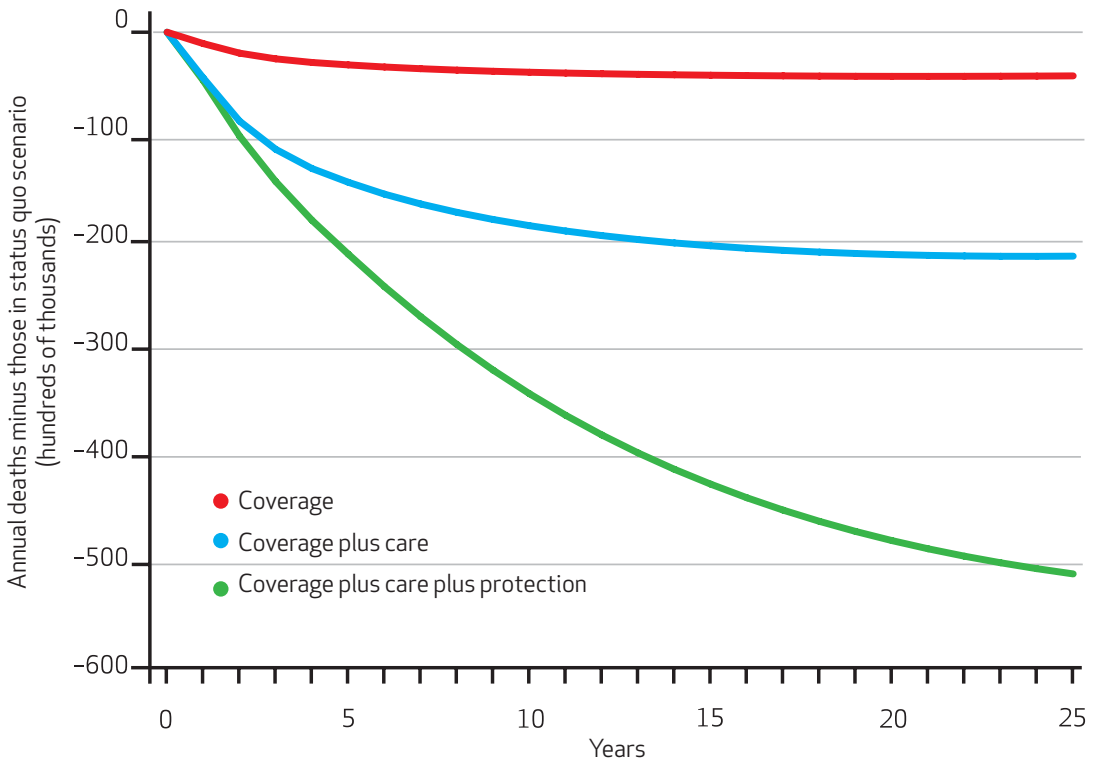

SOURCE Authors' analysis of the HealthBound policy simulation model. Nores Results are from the model's baseline setting. Uncertainty ranges are listed in the Appendix (see Note 4 in text).

Both the coverage and care interventions alone (care alone is not shown) would reduce deaths quickly within the first simulated year, but their effects would plateau after about ten years. The protection intervention alone (not shown), in contrast, would have a more gradual

\section{EXHIBIT 3}

Annual Costs (Health Care And Program Spending), Three Layered Intervention Scenarios, Year 0 To Year 25

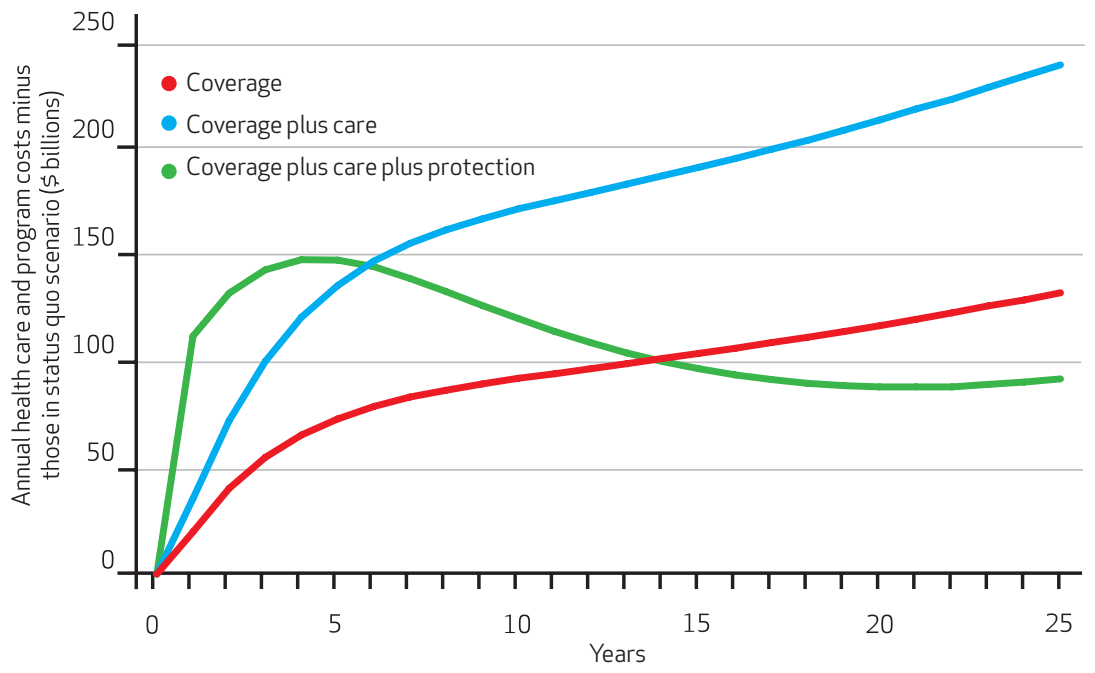

SOURCE Authors' analysis of the HealthBound policy simulation model. notes Results are from the model's baseline setting. Uncertainty ranges are listed in the Appendix (see Note 4 in text). influence but would ultimately produce large effects that would grow throughout the twentyfive years.

Coverage alone would prevent 25,000 deaths in year 3, 38,000 in year 10 , and 41,000 in year 25 , or 880,000 deaths cumulatively (Exhibit 2). Coverage plus care would prevent 110,000 deaths in year $3,180,000$ in year 10 , and 210,000 in year 25 (4.3 million cumulatively). Adding protection to the other two interventions would prevent 140,000 deaths in year 3, 340,000 in year 10, and 510,000 in year 25 (8.6 million cumulatively).

Individually, both coverage and care would increase costs, with the steepest rises occurring through year 7 but continuing increases through year 25 (care alone is not shown). These two interventions would increase health care use and amplify the cost-increasing impacts of price inflation and population aging. Protection, in contrast, would increase total costs for the first six years, reflecting the program's initial expenses, but would thereafter decrease total costs as program costs declined and disease and injury rates were reduced (not shown).

In year 25 the coverage intervention alone would increase costs by $\$ 133$ billion. Adding the care intervention would increase costs by $\$ 241$ billion, and adding protection to the other two interventions would result in an increase of $\$ 93$ billion (Exhibit 3).

In other words, the baseline simulation shows that when added to coverage and care, protection would save 90 percent more lives and reduce costs by 30 percent in year 10 . Those benefits would be even larger in year 25, when adding protection would save about 140 percent more lives and reduce costs by 62 percent. The timing and size of these savings varies somewhat in the optimistic and pessimistic scenarios, but the general pattern is stable despite those uncertainties.

\section{Discussion And Conclusions}

This analysis compared the likely impacts of three approaches to reducing avoidable deaths and lowering health care costs for Americans. The types of interventions tested include efforts to expand health insurance coverage, deliver better preventive and chronic care, and establish healthier behavioral and environmental conditions.

All three strategies have the potential to prevent hundreds of thousands, if not millions, of deaths while offering apparently good economic value. The benefits of expanding coverage occur quickly, and even larger short-term gains could be achieved through improving care or protec- 
tion. Neither care nor protection has a clear advantage in the first ten years, but after that, protection is likely to save more lives at a lower cost. Protection is a critical ingredient over the long term because it alone slows the growth in the prevalence of disease and injury-an important driver of both deaths and health care costs-and alleviates rather than exacerbates demand on limited health care capacity. By year 25 , the protection scenario is likely to save more lives than care while also saving money. Care, while saving lives, would increase costs.

The conclusions regarding the relative consequences of these simulated interventions are generally unaffected by changes in modeling assumptions, as indicated by the optimistic and pessimistic estimates (as well as by the threshold analyses reported in the Appendix). ${ }^{4}$ Despite this robustness, additional comparative modeling is warranted to explore the potential costs and health consequences across the spectrum of community, clinical, and insurance policy options and to assess the sensitivity of the findings to critical modeling assumptions. Furthermore, better data on intervention effectiveness and implementation costs, particularly for the care and protection interventions and especially over the longer term, would help narrow uncertainties and yield even stronger policy insights.

Still, planners may use insights from this study to move beyond a false choice between expanding coverage and improving care for individuals, on the one hand, and investing in populationbased strategies to ensure healthier living con- ditions, on the other hand. This dichotomized way of thinking has historically contributed to an unwillingness to invest in prevention initiatives that extend beyond the doctor's office. However, our results suggest that "upstream," protective interventions could effectively complement coverage and care, both by ensuring that people stay healthy for as long as possible and by reducing excess demand on an already overextended health care delivery system.

Another impediment to upstream action arises when planners and analysts look only ten years into the future. Our results confirm what other investigators have observed: A ten-year horizon tends to obscure the full effect of interventions that operate through indirect behavioral and environmental pathways, or that take time to diffuse through a large population. Because so much of the health and economic value from investments in healthier living conditions comes later, a twenty-five-year horizon is needed for a more complete appraisal of interventions.

Finally, because population-based prevention policies take longer to yield their full health benefits and economic returns, they should not be postponed or staged to follow initial successes from improving coverage and care. At least with regard to preventing avoidable deaths and lowering costs, the US health system's performance could be greatly improved in the short and longer term through wider coverage and better preventive and chronic care, combined with a strong national commitment to policies that enable healthier behavior and safer environments.
The findings and conclusions in this article are those of the authors and do not necessarily represent the official position of the Centers for Disease

Control and Prevention. The authors

acknowledge the contributions of Scott
Grosse, Linda Bilheimer, Cecilia Curry,

Thomas Frieden, and three anonymous peer reviewers.

\section{NOTES}

1 Milstein B, Homer J, Hirsch G. Analyzing national health reform strategies with a dynamic simulation model. Am J Public Health. 2010; 100(5):811-9.

2 The term HealthBound is used courtesy of Associates \& Wilson.

3 HealthBound estimates are based on information from the following national databases: the US census, vital statistics from the $\mathrm{CDC}$, National Health Expenditure Accounts, National Health Interview Survey, National Health and Nutrition Examination Survey, Behavioral Risk Factor Surveillance System, National Ambulatory Medical Care Survey, National Hospital Ambulatory Medical Care Survey, National Nursing Home Survey, and National Home Health Care Survey.

4 To access the Appendix, click on the
Appendix link in the box to the right of the article online.

5 Sterman JD. Business dynamics: systems thinking and modeling for a complex world. Boston (MA): Irwin/ McGraw-Hill; 2000.

6 Homer JB, Hirsch GB. System dynamics modeling for public health: background and opportunities. Am J Public Health. 2006;96(3):452-8.

7 Centers for Medicaid and Medicare Services. National health expenditures by type of service and source of funds, CY 1960-2009 [Internet]. Baltimore (MD): CMS; [cited 2011 Mar 22]. Available from: http:// www.cms.hhs.gov/NationalHealth ExpendData/02_NationalHealth AccountsHistorical.asp

8 Zhuang $\mathrm{J}$, Liang $\mathrm{Z}$, Lin $\mathrm{T}$, De Guzman F. Theory and practice in the choice of social discount rate for cost-benefit analysis: a survey [Internet]. Manila: Asian Development Bank; 2007 [cited 2010 Feb 9]. (ERD Working Paper No. 94). Available from: http://www.adb .org/Documents/ERD/Working_ Papers/WP094.pdf

9 Severens JL, Milne RJ. Discounting health outcomes in economic evaluation: the ongoing debate. Value Health. 2004;7(4):397-401.

10 Huang ES, Basu A, O'Grady MJ, Capretta JC. Using clinical information to project federal health care spending. Health Aff (Millwood). 2009;28(5):w978-90. DOI: 10.1377/ hlthaff.28.5.w978.

11 Steinbrook R. Health care reform in Massachusetts-expanding coverage, escalating costs. N Engl J Med. 2008;358(26):2757-60.

12 McGlynn EA, Asch SM, Adams J, 
Keesey J, Hicks J, DeCristofaro A, et al. The quality of health care delivered to adults in the United States. N Engl J Med. 2003;348(26): 2635-45.

13 Institute of Medicine. Crossing the quality chasm: a new health system for the 21st century. Washington (DC): National Academies Press; 2001.

14 Asch SM, Kerr EA, Keesey J, Adams JL, Setodji CM, Malik S, et al. Who is at greatest risk for receiving poorquality health care? N Engl J Med. 2006;354(11):1147-56.

15 Cunningham PJ. What accounts for differences in the use of hospital emergency departments across U.S. communities? Health Aff (Millwood). 2006;25(5):w324-36. DOI: 10.1377/hlthaff.25.w324.

16 Steven Asch and colleagues (see Note 14) estimate that 50-60 percent of patients receive care according to guidelines. Our higher estimate for provider adherence took into account the likely influence in their study of patient noncompliance and initial nondiagnosis, both of which are estimated separately in HealthBound. In addition, data from the Behavioral Risk Factor Surveillance System on the use of preventive services for hypertension, high cholesterol, and diabetes suggest that at least 70 percent of care meets current guidelines.

17 Farley TA, Dalal MA, Mostashari F, Frieden TR. Deaths preventable in the US by improvements in use of clinical preventive services. Am J Prev Med. 2010;38(6):600-9.

18 Frieden TR, Mostashari F. Health care as if health mattered. JAMA. 2008;299(8):950-2.

19 Centers for Disease Control and Prevention. What is the Community Guide? [Internet]. Atlanta (GA): CDC; [cited 2011 Mar 22]. Available from: http://www.thecommunity guide.org

20 Brownson RC, Haire-Joshu D, Luke DA. Shaping the context of health: a review of environmental and policy approaches in the prevention of chronic diseases. Annu Rev Public Health. 2006;27:341-70.

21 Centers for Disease Control and Prevention. Ten great public health achievements-United States, 1900-1999. MMWR Morb Mortal Wkly Rep. 1999;48(12):241-3.

22 Farrelly MC, Pechacek TF, Thomas KY, Nelson D. The impact of tobacco control programs on adult smoking. Am J Public Health. 2008;98(2): 304-9.

23 Grosse SD, Teutsch SM, Haddix AC. Lessons from cost-effectiveness research for United States public health policy. Annu Rev Public Health. 2007;28:365-91.

24 Estimated from the Behavioral Risk Factor Surveillance System, with reference to the combined preva- lence of smoking and physical inactivity.

25 Estimated from the Behavioral Risk Factor Surveillance System, with reference to perceived neighborhood safety.

26 These program costs may also be expressed in per capita terms, spread over the entire population rather than per beneficiary. When expressed in this way, the combined program costs for the behavioral and environmental interventions started at $\$ 269$ per capita in year 1 (uncertainty range: $\$ 50-\$ 632)$, declined to $\$ 177$ per capita by year 5 (uncertainty range: \$31-\$491) and \$139 per capita by year 13 (uncertainty range: $\$ 25$ $\$ 407)$, reaching $\$ 125$ per capita by year 25 (uncertainty range: \$23-\$365).

27 Farrelly MC, Pechacek TF, Chaloupka FJ. The impact of tobacco control program expenditures on aggregate cigarette sales: 19812000. Health Econ. 2003;22: 843-59.

28 Department of Health and Human Services. Reducing tobacco use: a report of the surgeon general [Internet]. Rockville (MD): Office of the Surgeon General; 2000 Aug [cited 2011 Apr 5]. Available from: http:// www.surgeongeneral.gov/library/ tobacco_use/

29 Department of Health and Human Services. The health consequences of involuntary exposure to tobacco smoke: a report of the Surgeon General [Internet]. Rockville (MD): Office of the Surgeon General; 2006 [cited 2011 Mar 22]. Available from: http://www.surgeongeneral.gov/ library/secondhandsmoke/report/ fullreport.pdf

30 Basiotis PP, Carlson A, Gerrior SA, Juan WY, Lino M. The healthy eating index: 1999-2000 [Internet]. Alexandria (VA): US Department of Agriculture, Center for Nutrition Policy and Promotion; 2002 [cited 2011 Mar 22]. Available from: http://www.cnpp.usda.gov/ publications/HEI/HEI99-00report .pdf

31 Mozaffarian D, Katan MB, Ascherio A, Stampfer MJ, Willett WC. Trans fatty acids and cardiovascular disease. N Engl J Med. 2006;354(15): 1601-13.

32 Angell SY, Silver LD, Goldstein GP Johnson CM, Deitcher DR, Frieden TR, et al. Cholesterol control beyond the clinic: New York City's trans fat restriction. Ann Intern Med. 2009; 151(2):129-34.

33 Kahn EB, Ramsey LT, Brownson RC, Heath GW, Howze EH, Powell KE, et al. The effectiveness of interventions to increase physical activity: a systematic review. Am J Prev Med. 2002;22(4 Suppl):73-107.

34 Dominici F, Peng RD, Zeger SL, White RH, Samet JM. Particulate air pollution and mortality in the United
States: did the risks change from 1987 to 2000? Am J Epidemiol. 2007;166(8):880-8.

35 Hingson R, Sleet DA. Modifying alcohol use to reduce motor vehicle injury. In: Geilen AC, Sleet DA, Diclemente RJ, editors. Injury and violence prevention: behavioral science theories, methods, and applications. San Francisco (CA): Jossey-Bass; 2006. p. 234-57.

36 Ford E, Capewell S. Proportion of the decline in cardiovascular disease due to prevention versus treatment: public health versus clinical care. Annu Rev Public Health. 2011;32: 5-22.

37 Danaei G, Ding EL, Mozaffarian D, Taylor B, Rehm J, Murray CJ, et al. The preventable causes of death in the United States: comparative risk assessment of dietary, lifestyle, and metabolic risk factors. PLoS Med. 2009;6(4):e1000058.

38 Pope CA, Burnett RT, Thurston GD, Thun MJ, Calle EE, Krewski D, et al. Cardiovascular mortality and longterm exposure to particulate air pollution: epidemiological evidence of general pathophysiological pathways of disease. Circulation. 2004; 109(1):71-77.

39 Centers for Disease Control and Prevention. Vital signs: adult seat belt use in the US [Internet]. Atlanta (GA): CDC; 2011 [cited 2011 Feb 28]. Available from: http://www.cdc.gov/ vitalsigns/SeatBeltUse/index.html

40 Centers for Disease Control and Prevention. Vital signs: tobacco use [Internet]. Atlanta (GA): CDC; 2010 [cited $2011 \mathrm{Feb} 28$ ]. Available from: http://www.cdc.gov/vitalsigns/ TobaccoUse/Smoking/index.html

41 Centers for Disease Control and Prevention. Vital signs: adult obesity [Internet]. Atlanta (GA): CDC; 2010 [cited $2011 \mathrm{Feb} 28$ ]. Available from: http://www.cdc.gov/vitalsigns/ AdultObesity/index.html

42 Centers for Disease Control and Prevention. Vital signs: high blood pressure and cholesterol [Internet]. Atlanta (GA): CDC; 2011 [cited 2011 Feb 28]. Available from: http:// www.cdc.gov/VitalSigns/ CardiovascularDisease/index.htm

43 Centers for Disease Control and Prevention. Vital signs: binge drinking [Internet]. Atlanta (GA): CDC; 2010 [cited 2011 Feb 28]. Available from: http://www.cdc.gov/ vitalsigns/BingeDrinking/index .html

44 Centers for Disease Control and Prevention. Best practices for comprehensive tobacco control programs [Internet]. Atlanta (GA): CDC; 2007 Oct [cited 2011 Mar 22]. Available from: http://www.cdc.gov/ tobacco/stateandcommunity/best_ practices/pdfs/2007/bestpractices_ complete.pdf

45 The only combination not shown is care plus protection, which we ex- 
cluded for visual clarity. This scenario closely resembles the combination of all three interventions in its shape over time, although the magnitude differs. For instance, care plus protection would prevent 305,000 deaths in year 10 and
472,000 in year 25; its effect on costs would be an increase of $\$ 28$ billion at year 10 and a saving of $\$ 35$ billion at year 25 . These results indicate that coverage contributes about 10 percent to the overall decline in deaths and contributes most of the cost in- crease in the scenario combining all

three interventions. There is no

"ordering effect" to the combina-

tions: all interventions in a combination were implemented at the same time.

\section{ABOUT THE AUTHORS: BOBBY MILSTEIN, JACK HOMER, PETER BRISS, DERON BURTON \& TERRY PECHACEK}

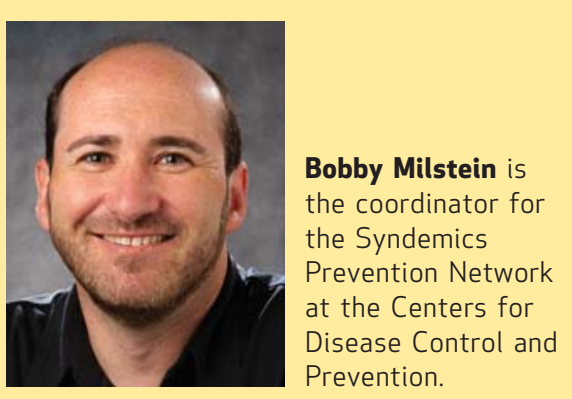

In their Health Affairs paper this month, Bobby Milstein and his coauthors apply their expertise from multiple disciplines to use a dynamic simulation model to test the effectiveness of three strategies to reduce deaths and curb health care costs: expanding health insurance coverage, delivering better preventive and chronic care, and protecting health by stimulating healthier behavior and improving environmental conditions. They conclude that protecting health is critical because it alone slows the growth in the prevalence of disease and injury and alleviates, rather than exacerbates, demand on limited health care capacity.

The authors have worked together through their respective affiliations for many years to bring greater structure and evidence to analyses of national health policy. Teaming up for this particular study, they developed models that provide evidence to support targeted policies and investments to improve health.

Milstein is the coordinator of the Syndemics Prevention Network at the Centers for Disease Control and Prevention (CDC), where he coordinates planning and evaluation activities to address chronic disease, environmental health, mental health, emergency preparedness, and health system improvement. He specializes in interactions among multiple health and social priorities and identifies innovations to improve health and health equity through system change. He earned a doctorate in public health science at Union Institute and University in Cincinnati, Ohio, and a master's in public health in behavioral science from Emory University's School of Public Health.

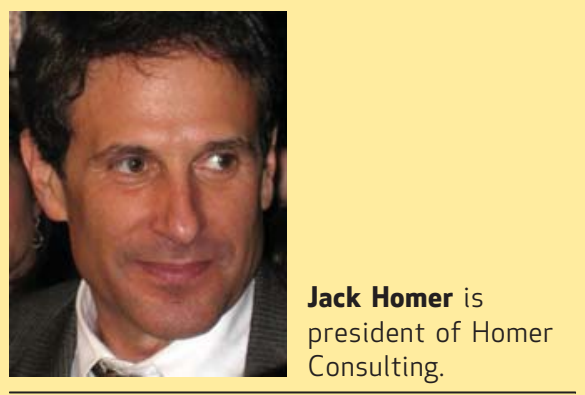

Jack Homer is president of Homer Consulting, where he uses system dynamics simulation methods to develop effective business strategies to inform public policy. He earned a doctorate in management at the Massachusetts Institute of Technology and a master's degree in statistics from Stanford University.

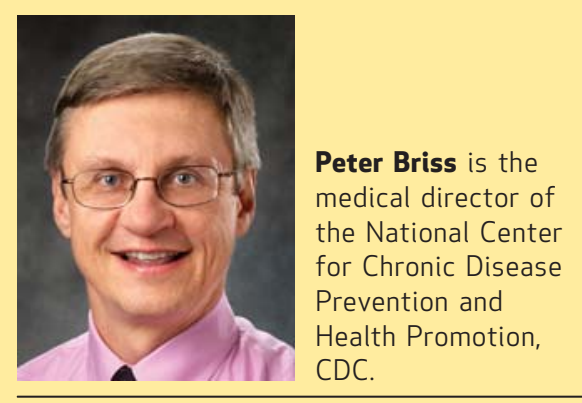

Peter Briss is the medical director of the CDC's National Center for Chronic Disease Prevention and Health Promotion. He has been with the CDC and the Commissioned Corps of the Public Health Service for twenty years. Board certified in internal medicine and preventive medicine, he is an active clinician at Grady Memorial Hospital, in Atlanta. Briss received a medical degree and training in internal medicine and pediatrics from Ohio State University and a master of public health degree in health management and policy from the University of Michigan.

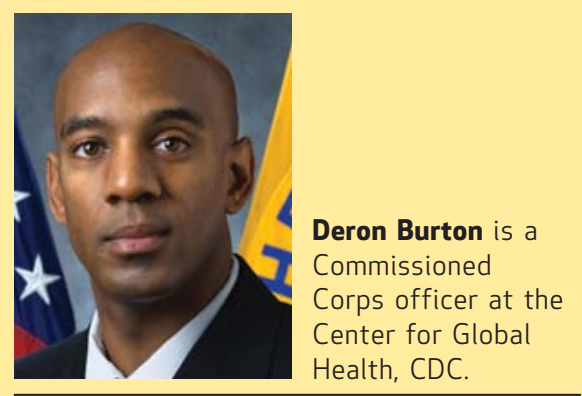

Deron Burton, a medical officer with the Public Health Service, is also a medical epidemiologist and the head of head of operations in western Kenya for the International Emerging Infections Program, in 
the CDC's Division of Global Disease Detection and Emergency Response, Center for Global Health, in Kisumu, Kenya. Board certified in preventive medicine, Burton earned his medical degree and a master of public administration at Johns Hopkins University, as well as a law degree from the University of California, Los Angeles.

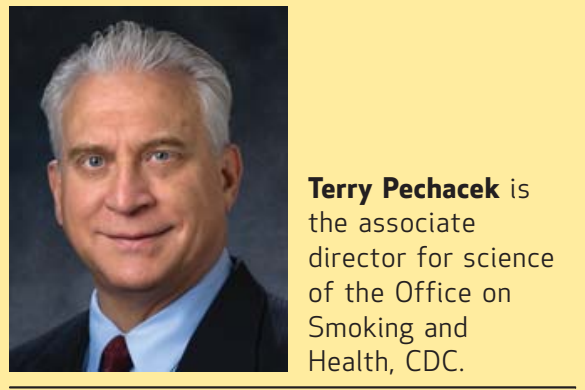

Terry Pechacek is the associate director for science of the Office on Smoking and Health at the CDC, where he helps develop policy for domestic and international efforts to reduce smoking. Before joining the $\mathrm{CDC}$, he directed research at the National Cancer Institute's Smoking Tobacco and Cancer Branch, in the Division of Cancer Prevention and Control. He earned a doctorate in counseling and clinical psychology and a master's degree in counseling psychology from the University of Texas, Austin. 